\title{
DESDOBRAMENTOS DA OPERAÇÃO LAVA-JATO NO COMBATE À CORRUPÇÃO NO BRASIL: UMA ANÁLISE A PARTIR DA PERSPECTIVA NEO-INSTITUCIONAL
}

\begin{abstract}
DEVELOPMENTS OF THE LAVA-JATO OPERATION IN COMBATING CORRUPTION IN BRAZIL: AN ANALYSIS FROM THE NEO-INSTITUTIONAL PERSPECTIVE
\end{abstract}

Recebido em 02.04.2019 Aprovado em 05.11.2019 Avaliado pelo sistema double blind review DOI: https://doi.org/10.12712/rpca.v13i3.28415

\author{
Alessandro Carlos da Silva Junior \\ alessandro.ufvadm@gmail.com \\ Departamento de Administração e Contabilidade/Universidade Federal de Viçosa - Viçosa/Minas Gerais, Brasil \\ ORCID: https://orcid.org/0000-0003-3467-9093
}

\section{Josiel Lopes Valadares}

adm josiel@yahoo.com.br

Programa de Pós-Graduação em Administração/PPGADM/Universidade Federal de Viçosa - Viçosa/Minas Gerais, Brasil

ORCID: https://orcid.org/0000-0002-2559-9617

\section{Suélem Viana Macedo}

\section{suelemvianamacedo@,hotmail.com}

Programa de Pós-Graduação em Administração - PPGADM/Universidade Federal de Viçosa - Viçosa/Minas Gerais, Brasil

ORCID: https://orcid.org/0000-0002-1610-1856

\section{Resumo}

Este ensaio teve como objetivo analisar, a partir do neo-institucionalismo, os desdobramentos da Operação Lava-Jato. Buscou-se compreender os principais arranjos institucionais que auxiliam no combate e controle da corrupção no Brasil. As discussões evidenciaram que devido à ameaça que a corrupção traz aos bens públicos e à democracia, o seu combate tornou-se central para a manutenção dos interesses sociais e políticos. Considera-se, a Operação Lava-Jato como uma instituição que coloca na agenda dos pesquisadores do campo de administração pública a necessidade de entender as falhas nos sistemas de gestão, controle e combate à corrupção e de regras institucionais.

Palavras-chave: Administração Pública. Corrupção. Operação Lava-Jato. Teoria Neo-institucional.

\begin{abstract}
This essay aimed to analyze, from neo-institutionalism, the developments of Lava-Jato Operation. We sought to understand the main institutional arrangements that help combat and control corruption in Brazil. The discussions showed that because of the threat that corruption poses to public goods and democracy, their fight has become central to the maintenance of social and political interests. The LavaJato Operation is considered as an institution that places on the agenda of researchers in the field of public administration the need to understand the flaws in management systems, control and anticorruption and institutional rules.
\end{abstract}

Keywords: Public administration. Corruption. Lava-Jato Operation. Neo-institutional theory. 


\section{Introdução}

A corrupção é um assunto proeminente no âmbito da burocracia pública, que tem adquirido cada vez mais centralidade nos debates políticos contemporâneos e na mídia nacional e internacional (AVRITZER et al., 2008; CARVALHO, 2008; FILGUEIRAS, 2011; MELO; SAMPAIO; OLIVEIRA, 2015; CALDAS; COSTA; PAGLIARUSSI, 2016). Trata-se de um fenômeno histórico, antigo e mutante, que apresenta variações de acordo com o tamanho e a natureza do Estado (CARVALHO, 2008). Presente no âmbito público e na seara privada, as suas implicações mais comuns, elencadas pela literatura, são a evasão de receita, a desaceleração do crescimento econômico, o direcionamento de recursos para atividades improdutivas, a instabilidade do regime político e das instituições que representam a base da democracia, bem como a desconfiança sobre as ações públicas (POWER; TAYLOR, 2011; FILGUEIRAS, 2011; SOUZA; SILVA; GOMES, 2017; MORAES; ANDION; PINHO, 2017).

As discussões sobre a sua presença no contexto brasileiro tornam-se ainda mais profícuas a partir dos casos de corrupção revelados no bojo da Operação Lava-Jato. Deflagrada pela Polícia Federal brasileira em março de 2014, a referida operação ainda se encontra em curso e já ensejou inúmeras investigações e prisões relacionadas à prática de atos corruptos no âmbito da administração pública, especialmente no nível federal. Segundo o Ministério Público Federal (2019), os esquemas criminosos revelados contavam com a participação de diversas empresas responsáveis pelo pagamento de propinas, de membros do Congresso Nacional brasileiro de diferentes partidos políticos, representantes do poder executivo e diretores de agências estatais, abarcando desde cargos políticos até a burocracia pública.

Em termos teóricos, na visão de Weber (1982), a burocracia é concebida como um tipo ideal, capaz de tornar plausível a compreensão da realidade das organizações sociais. O Estado, nesta perspectiva, passa a ser entendido como um mecanismo interpretativo das relações que permeiam os atores envolvidos no seu contexto (MORAES; MAESTRO FILHO; DIAS, 2003; GUERREIRO-RAMOS, 2006; LOUREIRO; OLIVIERI; MARTES, 2010; FARIA; MENEGHETTI, 2011). Na presente pesquisa, portanto, toma-se a burocracia como um instrumento de dominação, revestido de uma racionalidade baseada em regras, meios, fins e objetivos (WEBER, 1982; FARIA; MENEGHETTI, 2011).

O debate acerca da corrupção burocrática, desta maneira, vai em direção à ideia de que a burocracia, por potencializar segredos, conhecimentos e intenções, impacta o ambiente organizacional (WEBER, 1982). Quanto ao ponto, vale destacar que a corrupção é considerada um comportamento contrário às regras formais de conduta pública, visando a obtenção de ganhos pessoais (KLINGARD, 1994; KHAN, 1996; FILGUEIRAS, 2006). Nesse sentido, a fim de compreender as ações dos indivíduos, a perspectiva teórica neo-institucional apresenta o argumento de que o comportamento humano e as suas respectivas escolhas não são influenciados apenas por suas preferências individuais, mas, também, por instituições políticas e sociais que regulam as escolhas coletivas (MARCH; OLSEN 1989; NORTH, 1990; IMMERGUT, 1998; DIMAGGIO; POWELL 2001; HALL; TAYLOR, 2003).

No que se refere, mais especificamente, ao estudo da corrupção, a abordagem neo-institucional se fundamenta na noção de que os diferentes atores, no exercício de prerrogativas públicas ou na defesa de interesses privados, têm seu comportamento guiado pelo conjunto de incentivos criados pelo contexto institucional que os envolve (ROSE-ACKERMAN, 2010). A corrupção, por conseguinte, estaria relacionada à existência de situações de competição entre os agentes auto interessados, que buscariam (por meios lícitos ou ilícitos) alterar decisões coletivas para atingir seus interesses particulares, ainda que isso traga prejuízos ao bem-estar público (ROSE-ACKERMAN, 1978).

Assim, frente a problemática apresentada, este estudo, elaborado na forma de ensaio teórico, teve como objetivo geral analisar, a partir da perspectiva neo-institucional, a Operação Lava-Jato e os seus consequentes desdobramentos. Buscou-se, dessa forma, compreender os principais arranjos institucionais que auxiliam no combate e controle da corrupção burocrática no Brasil. Deste modo, considerando a contemporaneidade da temática, bem como os reflexos que as operações de combate à 
corrupção têm trazido para a administração pública, o presente trabalho discute as práticas corruptas mais recentes na seara do governo federal brasileiro.

Dado o contexto apresentado, ao definir a pesquisa como um ensaio teórico contribui-se para a literatura ao registrar um cenário específico de corrupção no contexto atual brasileiro. Em termos práticos, a pesquisa evidencia que as instituições são responsáveis por moldar o comportamento dos agentes, o que pode favorecer a prática de condutas que beneficiam interesses próprios. Toma-se a teoria neoinstitucional como uma importante lente para a compreensão de que o comportamento humano nas instituições públicas não se encerra a partir da constituição das regras, normas e instrumentos formais criados, mas é constituído, também, pelas práticas sociais compartilhadas.

O artigo está organizado em cinco seções, começando por esta introdução. A segunda apresenta uma breve análise da teoria neo-institucional. $\mathrm{Na}$ terceira seção é realizada uma análise do histórico e desdobramentos da Operação Lava-Jato. Já na quarta discute-se as instituições envolvidas na Lava-Jato e a abordagem neo-institucional. Por fim, na quinta seção, são apresentadas as considerações finais do estudo.

\section{A Abordagem Neo-institucional: Breves Considerações Teóricas}

O interesse pelas instituições como fatores determinantes para a compreensão da realidade social, embora pareça ser recente, também esteve presente na literatura clássica (CARVALHO; VIEIRA; SILVA, 2012; SILVA; PEREIRA; ALCÂNTARA, 2012). Autores como Aristóteles, John Locke, Montesquieu, Tocqueville e Émile Durkheim, a partir de enfoques diversos, tomaram as instituições sociais e políticas como unidades de análise de seus estudos (PERES, 2008). Entretanto, foi no final do século XIX que a abordagem institucional se tornou mais forte no campo das ciências sociais (NASCIMENTO 2009; CARVALHO; VIEIRA; SILVA, 2012). A partir da década de 1970, contudo, com a crise do paradigma comportamentalista, a teoria institucional ganhou novos contornos. Por este motivo, para diferenciar esta nova perspectiva das abordagens institucionais que predominaram no final do século XIX e início do século XX, a teoria institucional é tratada pela literatura sob o enfoque do velho e do neoinstitucionalismo.

Como forma de reação ao caráter normativo e formalista do antigo institucionalismo, o neoinstitucionalismo emerge como uma maneira de privilegiar a análise das instituições, uma vez que seus processos originários afetam o curso da história e podem estruturar de diversas maneiras a vida social e política (HALL; TAYLOR, 2003). As instituições políticas passam a ser consideradas como fatores fundamentais de compreensão de uma sociedade (LAMEIRÃO, 2007; MARCH; OLSEN, 2008). Na visão de Jensen e Mérand (2010, p. 82), uma instituição pode ser definida como "um conjunto de regras formais e normas informais que persiste através do tempo, mas também é sempre um padrão de relações sociais, que pode ser competitiva, oposicionista e caracterizada por relações de poder desiguais". Aliás, segundo Théret (2003), as instituições influenciam o comportamento dos agentes públicos e fornecem meios para subsidiar o processo de mudança. Assim, "a instituição serve de fio condutor para as ações dos indivíduos, guiando o seu comportamento” (OUTEIRO; GÓES; NASCIMENTO, 2016, p. 118).

O neo-institucionalismo, deste modo, fornece elementos que propiciam a análise das organizações de um governo, estabelecendo como funcionam as instituições, de que maneira são desenvolvidas as suas funções e como são tomadas as decisões. A ideia de instituições políticas, portanto, é fundamental para se compreender como a sociedade se comporta (HALL; TAYLOR, 2003). A abordagem neoinstitucional, de modo geral, é constituída por três vertentes principais: a histórica, a da escolha racional e a sociológica.

Na vertente histórica, o ponto central da vida política é o conflito entre grupos com diferentes interesses, que buscam explicações para a distribuição desigual do poder. Nesta perspectiva se reconhece que as características herdadas do passado (path dependence) influenciam no processo de criação e reforma 
institucional, combinando elementos macro e micro em suas análises, pois os processos históricos e as iniciativas particulares de grupos melhores posicionados na distribuição do poder podem explicar as transformações que ocorrem e ocorreram na instituição (HALL; TAYLOR, 2003; LAMEIRÃO, 2007; RIBEIRO, 2012; CARVALHO; VIEIRA; SILVA, 2012).

Os teóricos da escolha racional, segunda vertente do neo-institucionalismo analisada nesta pesquisa, acreditam que direitos como o de propriedade, a renda e os custos de transação são necessários para o crescimento e bom funcionamento das instituições (NORTH, 1990; HALL; TAYLOR, 2003). Segundo tal abordagem, os indivíduos compartilham um acervo de preferências e gostos, agindo de forma egoísta e individualista para que possam adquirir satisfação máxima, baseando-se em cálculos e estratégias (HALL; TAYLOR, 2003). Ao realizar escolhas, os indivíduos privilegiam aquelas que seriam mais agradáveis aos interesses individuais, em detrimento das mais favoráveis para a sociedade como um todo. Em virtude disso, surge a necessidade da criação de instituições que lhes possibilitem satisfazer suas necessidades, por meio de um processo de cooperação, uma vez que a sobrevivência destas depende do grau de utilidade apresentado.

Segundo Soares (2005, p. 24) o pressuposto acerca da racionalidade das ações está associado "à suposição de que o interesse dos atores dentro do aparato estatal é manter ou estender o próprio poder ou atribuições, assim como o interesse na arena privada é, de algum modo, explorar e obter vantagens do Estado". Nesse contexto, considera-se que as pessoas agem, de fato, de acordo com as prescrições, ou seja, ela indica às pessoas como escolher e atuar a fim de alcançar suas metas da melhor forma possível (HALL; TAYLOR, 2003). Portanto, na perspectiva da escolha racional, a criação das instituições é consequência da necessidade de maximização das preferências por parte dos atores. Já a sua manutenção é decorrência do oferecimento de benefícios aos interessados e não das formas institucionais concorrentes (HALL; TAYLOR, 2003; RIBEIRO, 2012).

A última linha de pensamento do neo-institucionalismo é a abordagem sociológica, que foi influenciada pelos estudos de Karl Marx, Max Weber e Durkheim (JENSON; MÉRAND, 2010). Os pensadores dessa escola entendem as instituições "como as estruturas morais e cognitivas nas quais os indivíduos estão imersos e a partir das quais agem, interpretam o mundo e realizam suas escolhas" (LAMEIRÃO, 2007, p.15). Assim, as instituições são criadas com o intuito de fornecer aos indivíduos um modelo de comportamento social, por meio dos símbolos e da cultura, de modo que a sobrevivência dessas instituições depende da aderência dos indivíduos a esses modelos estabelecidos.

O Quadro 1 sintetiza as principais características das três abordagens do neo-institucionalismo evidenciadas, tendo em conta a relação entre o comportamento e a instituição, bem como os motivos destas surgirem e se modificarem. 
Quadro 1. Síntese das abordagens da teoria neo-institucional

\begin{tabular}{|c|c|c|c|}
\hline Neo-institucionalismo & Impacto das Instituições & $\begin{array}{c}\text { Comportamento dos } \\
\text { Atores }\end{array}$ & $\begin{array}{c}\text { Autores } \\
\text { (Referências) }\end{array}$ \\
\hline \multirow{4}{*}{ Institucionalismo Histórico } & $\begin{array}{l}\text { O conflito entre grupos rivais é } \\
\text { central na vida política }\end{array}$ & \multirow{2}{*}{$\begin{array}{l}\text { Os indivíduos recorrem a } \\
\text { protocolos estabelecidos ou } \\
\text { a modelos de } \\
\text { comportamento já } \\
\text { conhecidos para atingir seus } \\
\text { objetivos } \\
\end{array}$} & \multirow{4}{*}{$\begin{array}{l}\text { - Hall e Taylor } \\
\text { (2003) } \\
\text { - Lameirão (2007) } \\
\text { - Ribeiro (2012) } \\
\text { - Carvalho, Vieira e } \\
\text { Silva (2012) }\end{array}$} \\
\hline & $\begin{array}{c}\text { Há associação de instituições com } \\
\text { as regras editadas pelas } \\
\text { organizações formais }\end{array}$ & & \\
\hline & $\begin{array}{l}\text { As instituições criam espaços de } \\
\text { resistência por estruturarem as } \\
\text { próprias decisões } \\
\end{array}$ & \multirow{2}{*}{$\begin{array}{l}\text { A organização institucional } \\
\text { estrutura o comportamento } \\
\text { coletivo }\end{array}$} & \\
\hline & $\begin{array}{l}\text { Propriedades herdadas do passado } \\
\text { influenciam na construção das } \\
\text { novas instituições (path dependence) }\end{array}$ & & \\
\hline \multirow{2}{*}{$\begin{array}{l}\text { Institucionalismo da } \\
\text { Escolha Racional }\end{array}$} & $\begin{array}{l}\text { As instituições estruturam as } \\
\text { intenções e possibilidades de } \\
\text { escolhas dos agentes }\end{array}$ & $\begin{array}{l}\text { Os agentes almejam ganhos } \\
\text { de trocas }\end{array}$ & \multirow{2}{*}{$\begin{array}{l}\text { - North (1990) } \\
\text { - Hall e Taylor } \\
\quad(2003) \\
\text { - Soares (2005) } \\
\text { - Ribeiro (2012) }\end{array}$} \\
\hline & $\begin{array}{l}\text { As instituições são regulamentos } \\
\text { fixos às escolhas dos agentes }\end{array}$ & $\begin{array}{l}\text { As instituições constrangem } \\
\text { comportamentos e ações } \\
\text { humanas }\end{array}$ & \\
\hline \multirow{2}{*}{$\begin{array}{l}\text { Institucionalismo } \\
\text { Sociológico }\end{array}$} & $\begin{array}{l}\text { Intencionalidade humana } \\
\text { determina as transformações } \\
\text { institucionais. }\end{array}$ & \multirow{2}{*}{$\begin{array}{l}\text { As instituições são } \\
\text { fornecedoras de esquemas e } \\
\text { modelos cognitivos } \\
\text { (símbolos) que moldam as } \\
\text { ações humanas. }\end{array}$} & \multirow{2}{*}{$\begin{array}{l}\text { - Jenson e Mérand } \\
\text { (2010) } \\
\text { - Lameirão (2007) }\end{array}$} \\
\hline & $\begin{array}{c}\text { Os atores julgam o desempenho } \\
\text { institucional e são determinantes } \\
\text { para sua sobrevivência }\end{array}$ & & \\
\hline
\end{tabular}

Fonte: Elaborado pelos autores com base na literatura consultada.

A partir da análise contida no Quadro 1, verifica-se que no institucionalismo histórico as instituições são reflexos de seu percurso histórico, de modo que os atores agem a partir de comportamentos já existentes. Já na perspectiva da escolha racional, as instituições oferecem regras fixas que regulam o comportamento dos agentes. Estes, por sua vez, buscam a maximização de seus interesses. Por fim, na abordagem sociológica as instituições são resultados da intencionalidade humana. É a ação humana que determina a sobrevivência das instituições, ou seja, no institucionalismo sociológico as instituições são definidas para além das regras, procedimentos ou normas formais, incluindo, também, os sistemas de símbolos, os aparatos cognitivos e as questões morais que direcionam a ação humana. Emerge neste debate a ressignificação das instituições pela cultura compartilhada e a toma-se a realidade como socialmente construída (HALL; TAYLOR, 2003; PERES, 2008; RIBEIRO, 2012).

Apesar das diferenças existentes entre as abordagens neo-institucionalistas, para um bom desempenho dos resultados políticos, tornam-se necessárias instituições que fiscalizem de maneira efetiva as intencionalidades de seus atores, a fim de evitar comportamentos egoístas que conduzam a prática de atos corruptos. Conforme destacam March e Olsen (2008), a visão neo-institucionalista permite fazer um exame das políticas públicas, da mudança institucional e da relevância das instituições para esta dinâmica. Ademais, observa-se que a teoria institucional permite romper com o exame funcionalista ou instrumentalista das instituições públicas, atentando-se para os conflitos sociais e o compartilhamento de símbolos e elementos cognitivos no tecido social.

Nos estudos de North (1990), Dimaggio e Powel (2001), Hall e Taylor (2003), Théret (2003) e March e Olsen (2008), verificam-se evidências de que as abordagens institucionais são fundamentais para a compreensão do comportamento humano nas instituições, sendo possível notar, ainda, suas implicações nos processos de mudanças institucionais. No campo organizacional, a abordagem institucional, a partir de perspectivas teóricas e empíricas, também foi realizada por Assis (2011), Cavalcante (2011), Cechelaine et al., (2013) e Fialho e Martins (2016). Carvalho, Vieira e Silva (2012), entretanto, alertam os leitores para 
uma trajetória conservadora da teoria institucional, sobretudo, pela escassez de discussões teóricas em torno dos debates sociais no Brasil.

No que se refere ao estudo da corrupção, Rose-Ackerman (2010) destaca que a abordagem neoinstitucionalista se fundamenta na noção de que os diferentes atores, no exercício de prerrogativas públicas ou na defesa de interesses privados, têm seu comportamento guiado pelo conjunto de incentivos criados pelo contexto institucional que os envolve. A corrupção, nesse sentido, estaria relacionada à existência de situações de competição entre os agentes auto interessados que buscariam (por meios lícitos ou ilícitos) alterar decisões coletivas para atingir seus interesses particulares, ainda que isso traga prejuízos ao bem-estar público (ROSE-ACKERMAN, 1978).

A abordagem do neo-institucionalismo, nesse contexto, coloca o Estado e a burocracia como atores relevantes, que detêm a capacidade de influenciar na formulação de leis e na implementação de políticas sociais. Logo, a corrupção deixa de ser explicada apenas a partir de elementos da estrutura social, considerando, também, o processo decisório dos atores envolvidos. Nesse aspecto, à medida que a corrupção passou a ser observada como uma ameaça aos bens públicos e à sobrevivência da democracia, o seu combate tornou-se um tema central do enfoque neo-institucionalismo (MATIAS-PEREIRA, 2005).

Vale destacar, que os governos brasileiros têm criado uma série de órgãos burocráticos com a função de monitorar, fiscalizar e responsabilizar os entes públicos (MATIAS-PEREIRA, 2005; ARANTES et al., 2010; FILGUEIRAS; ARANHA, 2011). São exemplos de tais órgãos, em nível federal, a Controladoria Geral da União (CGU), o Ministério Público Federal ou Estadual o Tribunal de Contas da União (TCU) e a Polícia Federal (PF). Com a promulgação da Constituição Federal de 1988 (BRASIL, 1988), o papel da sociedade civil frente às decisões políticas e ao controle das atividades executadas pelos governos também ganhou novos contornos (AVRITZER, 2009; GUIMARÃES, 2010; VENTURA, 2016). Além do voto, mecanismos como a iniciativa popular, o referendo, o plebiscito, os conselhos gestores, o orçamento participativo, são exemplos de novas formas do cidadão participar da gestão pública.

Assim, como a corrupção tende a ocasionar ineficiência e injustiça, colaborando para o crescimento das desigualdades e para a perda de legitimidade dos governantes (PNUD, 2004), o seu combate e controle devem ser enfrentados de maneira firme e resolutiva pelo Estado.

\section{A Operação Lava-Jato: Histórico e Desdobramentos}

A Operação Lava-Jato, segundo o Ministério Público Federal (MPF, 2017a), é a maior investigação sobre corrupção conduzida até hoje no Brasil. Deflagrada em março de 2014, no final de 2018 o caso já se encontrava em sua $52^{\mathrm{a}}$ fase (BRASIL, 2017). As investigações que culminaram na referida operação iniciaram em 2009, a fim de apurar crimes de lavagem de dinheiro praticados por organizações lideradas por doleiros que relacionavam entre si. Uma delas usava uma rede de lavanderias e postos de combustíveis para movimentar os valores de origem ilícita, surgindo daí o nome "Lava-Jato", dado à operação. As investigações conduzidas revelaram a participação no esquema criminoso de membros do Congresso Nacional brasileiro de diversos partidos políticos, de representantes do poder executivo federal e estadual, de diretores de grandes agências estatais e de empresários das maiores empreiteiras do país (MPF, 2017a; BRASIL, 2017).

Quanto aos desdobramentos da operação, a sua primeira fase, iniciada em março de 2014 perante a $13^{a}$ Vara Federal Criminal da Subseção Judiciária Curitiba, teve como foco a investigação de organizações criminosas lideradas por doleiros, que eram responsáveis pela movimentação financeira e lavagem do dinheiro desviado. As apurações revelaram um esquema criminoso de corrupção envolvendo a Petrobras, empresa de capital aberto cujo acionista majoritário é o governo brasileiro. Segundo o Ministério Público Federal (MPF, 2017b), verificou-se que há pelo menos dez anos a estatal beneficiava grandes empreiteiras 
em troca de propinas pagas aos seus executivos e a outros agentes públicos, por meio de operadores financeiros.

Para fraudar as licitações, simulando uma concorrência real, e conseguir contratos com a Petrobras, as empreiteiras envolvidas organizavam-se em forma de cartel. Os valores acordados com os diretores da Petrobras eram calculados e ajustados em encontros sigilosos, nos quais se definia quem ganharia o contrato e qual seria o seu preço. Para viabilizar o esquema criminoso, a quantia ajustada com as empreiteiras era superfaturada em favor de interesses privados de políticos e em prejuízo aos cofres públicos. Esse sistema envolveu não só diretores da estatal e os membros dos partidos políticos que se beneficiam com os desvios financeiros, mas, também, inúmeros agentes públicos da Petrobras (MPF, 2017b).

As investigações constataram, ainda, que o esquema de desvios de recursos era operacionalizado pela Diretoria de Abastecimento, Diretoria de Serviços e Diretoria Internacional da estatal, sendo que todos os respectivos diretores foram indicados por representantes de partidos políticos diversos que se favoreciam com os desvios. Os operadores financeiros de cada uma das diretorias eram responsáveis por intermediar o pagamento da propina e entregá-la aos beneficiários, disfarçada de dinheiro limpo, por meio de movimentações financeiras no exterior, contratos simulados com empresas de fachada ou pagamento de bens (MPF, 2017a). Em virtude dos desdobramentos das investigações, que culminaram na descoberta de novos esquemas de desvios de dinheiro e pagamento de propinas, as fases iniciais da Lava-Jato tiveram como objeto a apuração de atos fraudulentos relacionados à Petrobras que envolviam políticos de diferentes partidos e as maiores empreiteiras do Brasil.

$\mathrm{Na}$ fase inicial da operação, inúmeros mandados de busca e apreensão, de prisão preventiva e temporária e de condução coercitiva foram expedidos pela Justiça Federal no estado do Paraná e cumpridos em diversos estados brasileiros, culminando na prisão de parte dos doleiros e de ex-diretores da estatal que participavam do esquema criminoso (MPF, 2017a; BRASIL, 2017). Nesse contexto, destaca-se que a utilização da colaboração premiada ao longo das investigações propiciou a descoberta de novos atores envolvidos e maiores esclarecimentos quanto ao funcionamento dos desvios, resultando na deflagração das fases subsequentes da operação. Esse instrumento jurídico está previsto na Lei Federal $\mathrm{n}^{\circ}$. 12.850/2013 (BRASIL, 2013), conhecida como Lei de Combate às Organizações Criminosas, e tem como objetivo incentivar os investigados a colaborarem com a Justiça em troca da concessão de benefícios, como a diminuição da pena, alteração do regime de cumprimento da pena ou mesmo, em casos excepcionais, a isenção da pena, podendo ocorrer de duas formas diversas.

Na primeira, o acusado revela informações a fim de que tal cooperação seja levada em consideração pelo judiciário no momento da aplicação da pena. Na segunda, é realizado um acordo entre o investigado e o Ministério Público formalizado por meio de um contrato no qual são definidas as condições para que a cooperação seja premiada e quais os benefícios concedidos (MPF, 2017b). Conforme previsto na Lei Federal no. 12.850/2013 (BRASIL, 2013), realizado o acordo, o respectivo termo será remetido ao juiz para homologação, que deverá verificar sua regularidade, legalidade e voluntariedade.

Depois de homologado, o colaborador poderá ser ouvido pelo membro do Ministério Público ou pelo delegado de polícia responsável pelas investigações. Os acordos celebrados pelos investigados com o Ministério Público Federal aliados à documentação e materiais apreendidos, aos dados financeiros obtidos por meio de quebra de sigilo bancário e às interceptações telefônicas realizadas, permitiram o avanço da operação e a descoberta de um grande esquema de desvios de recursos públicos que não se restringia apenas à lavagem de dinheiro por meio de postos de gasolina (MPF, 2017a; BRASIL, 2017).

Além disso, também foram celebrados Acordos de Leniência entre o Ministério Público Federal e as empreiteiras investigadas, tendo estas se comprometido a revelar fatos ilícitos praticados na Petrobras e em outras esferas de poder, envolvendo agentes políticos de governos federal, estaduais, municipais e estrangeiros (MPF, 2017a). Entende-se os acordos de leniência, conforme Ritt (2017), como uma 
modalidade de acertamento administrativo, quando observado práticas ilícitas de pessoas jurídicas contra a administração pública. A autora complementa que o acordo é considerado um instrumento alternativo, que se for bem aplicado tem as mesmas finalidades que as sansões tradicionais, mas oferece uma harmonização das relações sociais, causando desincentivo para a prática de atos ilícitos (RITT, 2017).

Os acordos de leniência, nesse contexto, permitem a preservação das empresas e a continuidade de suas atividades, estabelecendo mecanismos destinados a assegurar a adequação e a efetividade das práticas de integridade, prevenindo a ocorrência de novos atos ilícitos. Embora o seu valor central repouse na obtenção de informações e documentos sobre práticas ilícitas, as empresas também se obrigaram ao pagamento de substanciais quantias em dinheiro aos cofres públicos brasileiros, caracterizando, em termos monetários, o maior acordo feito em um caso de corrupção na história mundial (BRANDT et al., 2016; MPF, 2017a).

Destaca-se, ademais, que em decorrência da amplitude do caso e da grande quantidade de materiais para serem analisados, o procurador-geral da República designou um grupo de procuradores da República, denominado como "força-tarefa", para conduzir a operação. As investigações e os respectivos processos provenientes da Lava-Jato tramitam na $13^{a}$ Vara Federal Criminal da Subseção Judiciária Curitiba, especializada em crimes financeiros e de lavagem de ativos, porque os primeiros fatos investigados envolviam crimes de lavagem de dinheiro praticados no estado do Paraná (MPF, 2017a).

Entretanto, como depoimentos e provas revelaram a possível participação de parlamentares, que possuem foro por prerrogativa de função (privilegiado) conforme previsto no art. 102 da Constituição Federal do Brasil de 1988 (BRASIL, 1988), as investigações e os processos foram encaminhados para o Supremo Tribunal Federal (STF), órgão do judiciário competente para julgar e processar originariamente os membros no Congresso Nacional nos casos de infração penal comum e os investigados que mantiveram algum tipo de relação com os mesmos (MPF, 2017a). Na hipótese de denúncias direcionadas aos governadores de estados compete ao Superior Tribunal de Justiça processá-los e julgá-los originariamente.

Nas fases seguintes da operação, além de fatos ocorridos no âmbito da Petrobras, desvios de recursos ocorridos em outros órgãos públicos federais também foram abrangidos pela investigação. Tais investigações resultaram, posteriormente, na prisão dos altos executivos de grandes empreiteiras com atuação no mercado nacional e internacional, de políticos conhecidos, ex-ministros do governo federal e ex-governadores, profissionais do marketing político e importantes empresários brasileiros. Todos estavam envolvidos em crimes de corrupção ativa e passiva, gestão fraudulenta, lavagem de dinheiro, organização criminosa, obstrução da justiça, operação fraudulenta de câmbio e recebimento de vantagem indevida (MPF, 2017a; BRASIL, 2017).

Segundo informações do Ministério Público Federal (2018), estima-se que o volume de recursos desviados, considerando apenas a Petrobras, esteja na casa de bilhões de reais. Parte desse dinheiro já retornou aos cofres públicos por meio da repatriação de valores que encontravam-se depositados em contas no exterior. Ainda como desdobramento das investigações, a partir de dados obtidos com os acordos de leniência e a colaboração premiada, diversos novos inquéritos foram instaurados contra políticos e empresários, com acusações de envolvimento em crimes de corrupção e lavagem de dinheiro, incluindo um ex-presidente da república, que foi incialmente condenado em primeira e segunda instância e, inclusive, preso (MPF, 2019).

Nessa perspectiva, a mídia, sobretudo, a mass media (LUBENOW, 2012) teve e tem um impacto no processo de legitimação da Operação Lava-Jato e em suas investigações. A posição social dos investigados, o impacto político das prisões e das decisões proferidas pelo juiz de primeira instância e ministros do STF que conduzem as investigações, bem como o conteúdo das colaborações premiadas, contribuíram para a vocação midiática da operação. Outro fator relevante na análise da repercussão da 
Operação Lava-Jato na mídia é a sua íntima relação com as redes sociais, que conectam um número ilimitado de pessoas.

Todavia, a capacidade dos meios de comunicação de produzir consenso sobre os assuntos divulgados os converte em expressivo instrumento de controle social, na medida em que são eles que escolhem o que será apresentado como importante para a sociedade, definindo como a informação deve ser compreendida (GOMES, 2016). A mídia, portanto, contribuiu para transformar os atores processuais em mitos, que encarnaram valores opostos e extremos, de um lado o juiz que conquistou o apoio uma parcela considerável dos brasileiros, e de outro os acusados poderosos.

Vale destacar, entretanto, que apesar da mídia considerar a Lava-Jato positiva para o país, ela também acredita que a operação necessita passar por reparos (ESTADÃO, 2017a). O trabalho do Ministério Público Federal foi questionado por excessos no modo de conduzir as investigações (ESTADÃO, 2017a). Ademais, embora a Lava-Jato tenha revelado vários esquemas de corrupção, haveria uma limitação no foco do trabalho da operação, pois as investigações iniciais teriam dedicado muita atenção a crimes contra o dinheiro público, se esquecendo de crimes envolvendo dinheiros particulares, gerando a impressão de que as instituições estão preocupadas apenas com o Estado (ESTADÃO, 2017a). Para a mídia, um outro fator que limita a Operação Lava-Jato diz respeito à atuação do STF em relações aos procedimentos penais contra pessoas com foro privilegiado, nos quais os processos têm desfechos lentos (Estadão, 2017a), que acabam privilegiando os investigados (ESTADÃO, 2017b).

Segundo Bobbio (2000), um escândalo é a corrupção que vem a público. Assim, dar publicidade à corrupção é uma forma de combate a esta prática, de modo que a imprensa torna-se imprescindível para a formação da noção do nível de corrupção. É necessário, contudo, que a veiculação da informação seja imparcial e retrate de modo verdadeiro todas as circunstâncias. Segundo Avritzer et al. (2008), os escândalos midiáticos representam a ação de controle social mais saliente em termos de luta contra a corrupção, pois permitem dar conhecimento à opinião pública. Aliás, pesquisas recentes evidenciam como as redes sociais podem ser utilizadas para pluralização, distribuição e consumo de diversos temas presentes na esfera pública (JACKSON; VALENTINE, 2014; COLLEONI, et al., 2014).

Todavia, é importante salientar o efeito retórico e de discurso polarizador presentes neste contexto, principalmente, pela baixa regulação do conteúdo produzido, reproduzido e consumido (BARROS, 2014), pois a internet e as redes sociais tornam-se lugares comuns de amplas disputas discursivas (PAIVA; GARCIA; ALCÂNTARA, 2016). Deste modo, o papel da mídia de massa hegemônica, ou seja, dos canais capazes de disseminar discursos de amplo alcance, pode acabar interferindo nos processos de legitimação da Operação Lava-Jato (VAARA; TIENARI, 2011).

Destaca-se, ainda, que no início das investigações, quando as notícias sobre a Operação Lava-Jato já dominavam os meios de comunicação do país, o Ministério Público Federal iniciou uma campanha com o objetivo principal de conseguir apoio popular para a propositura de um projeto de lei, cujo objetivo é estabelecer medidas contra a corrupção e demais crimes contra o patrimônio público e combate o enriquecimento ilícito de agentes públicos. Por meio de voluntários em todo o país, a iniciativa coletou mais de dois milhões de assinaturas em apoio à campanha, para que as propostas pudessem ser apresentadas ao Congresso Nacional, por meio de projeto de iniciativa popular, que assumiu a forma do PL no. 4.850/2016 (MPF, 2017b).

A partir da análise dos acontecimentos que sucederam o início das investigações, pode-se inferir que a Operação Lava-Jato atua como um instrumento de combate à prática de atos corruptos por políticos e servidores públicos, que primavam pelos interesses privados em detrimento dos interesses da sociedade. Além de trazer ao público os detalhes do esquema criminoso que há anos desviava recursos da Petrobras, por meio de um sistema de favorecimento de empresas e pagamento de propina, as investigações e as consequentes prisões e condenações dos integrantes demonstram que o combate à corrupção atua, de igual modo, sobre os políticos e partidos políticos mais influentes do país. 
Acredita-se, ainda, que outro fator relevante da operação refere-se aos seus desdobramentos, que permitiram não só a desarticulação do esquema de corrupção que trouxe um grande rombo para os cofres públicos, mas, também, a descoberta de novos desvios de dinheiro em outros órgãos e esferas de poder. Ademais, devido à grande proporção que a Lava-Jato ganhou em âmbito nacional e internacional, a questão do combate à corrupção no país voltou a ocupar, com maior ênfase, as discussões sociais e os discursos políticos.

\section{Instituições envolvidas na Operação Lava-Jato e a abordagem Neo-institucional: aproximações e reflexões}

Desde que foi deflagrada, a Lava-Jato vem investigando uma série de crimes relacionados à lavagem de dinheiro, recebimento de propinas, favorecimento de empresas, entre outros, se tornando, por isso, um importante instrumento de combate à corrupção no Brasil (CHADE, 2016). De modo geral, as investigações são conduzidas pela Polícia Federal (PF) e os inquéritos policiais instaurados são encaminhados ao Ministério Público Federal (MPF), responsável por promover a ação penal por meio do oferecimento da denúncia. Após análise de todos os fatos narrados pelo órgão ministerial, cabe ao judiciário receber ou não a acusação. Havendo indícios da ocorrência de crime, dá-se início ao processo judicial, no qual é apurada a veracidade das condutas ilícitas informadas, culminado na aplicação da pena relativa à infração praticada, caso seja devidamente comprovada a prática do crime (MPF, 2017a).

Conforme o Ministério Público Federal (2017a), além do auxílio da Polícia Federal, a investigação contou com o apoio da Inteligência da Receita Federal, do Conselho de Controle das Atividades Financeiras; do Conselho Administrativo de Defesa Econômica (CADE); do Ministério da Justiça, por meio do Departamento de Recuperação de Ativos e de Cooperação Jurídica Internacional; do Tribunal de Contas da União (TCU) e a da Controladoria Geral da União (CGU), que passou integrar, desde maio de 2016, o Ministério da Fiscalização, Transparência e Controle, que atua em todas as atividades relativas à defesa do patrimônio público e ao incremento da transparência da gestão, por meio das atividades de controle interno, auditoria pública e prevenção e combate à corrupção (BRASIL, 2016). As interações entre esses órgãos de controle encontram-se delimitadas na Figura 1.

Figura 1. Instituições envolvidas nas investigações da Operação Lava-Jato

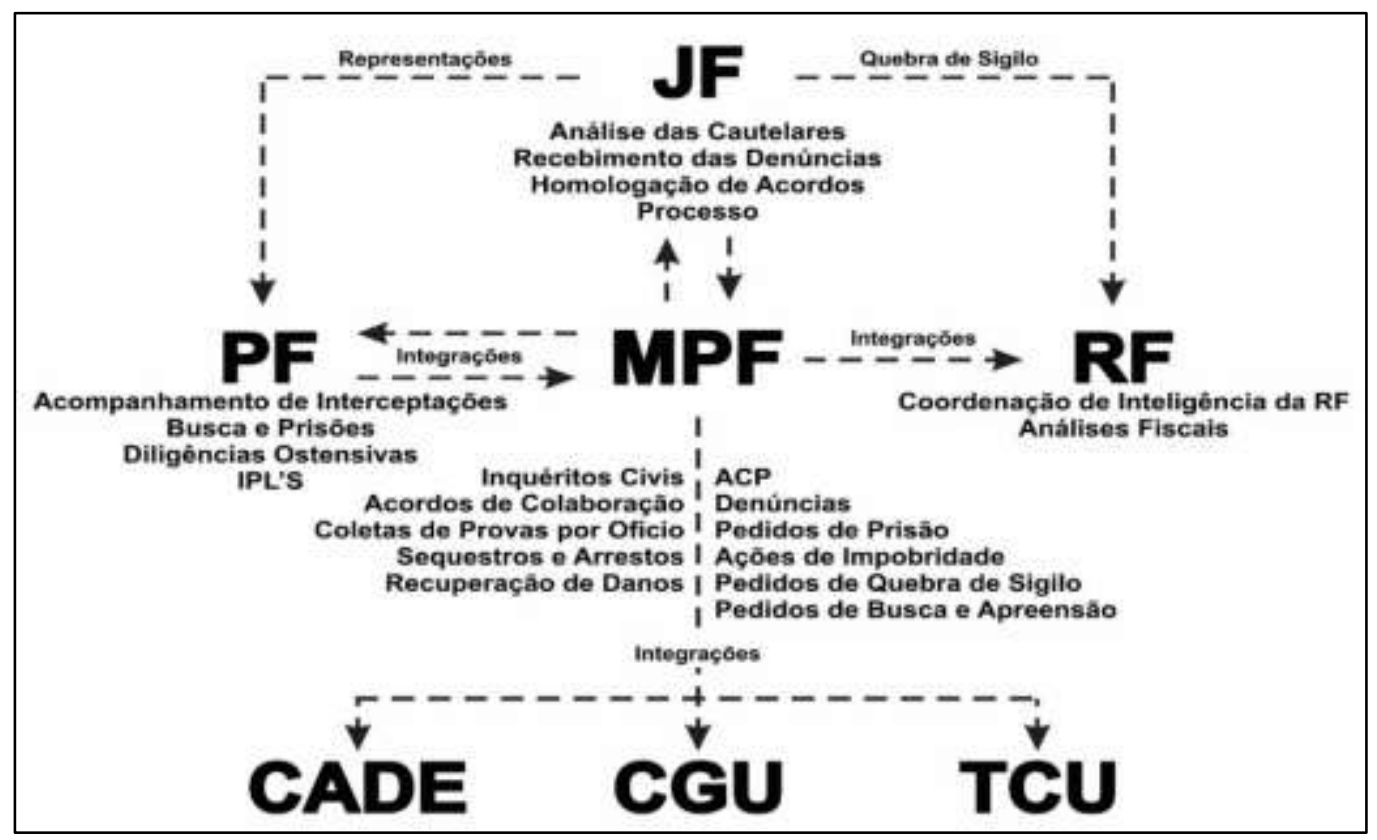

Fonte: Elaborado pelos autores com base no MPF (2017a). 
Diante do arranjo institucional destacado acima, observa-se que a pesquisa contribui para o entendimento de que os processos estabelecidos pela governança democrática atual expõem o fato histórico de que há uma hipertrofia do executivo brasileiro (LOUREIRO; OLIVIERI; MARTES, 2010). Não obstante, este estudo evidencia que o conceito da burocracia no Brasil deve ser compreendido para além do poder executivo. O poder judiciário, na perspectiva analisada, torna-se central para que instrumentos de controle externo da corrupção sejam aprimorados e aplicados de forma eficiente. Especificamente no caso da Operação Lava-Jato, é possível relacionar os comportamentos dos atores da burocracia envolvidos na investigação com as três principais vertentes da abordagem neo-institucional.

Inicialmente, observou-se que a conduta corrupta dos acusados é fruto de uma crença de que quem está no poder é imune à justiça, sendo um reflexo do path dependence presente no institucionalismo histórico. Tal comportamento pode ser visto, também, por meio da perspectiva da escolha racional, visto que os agentes corruptos decidem agir de ilegalmente por questão de poder e influência ou, na maioria das vezes, apenas para se beneficiarem financeiramente. A Operação Lava-Jato, portanto, deixou mais evidente que a punição decorrente da prática de atos corruptos pode atingir, de igual modo, o alto escalão da política brasileira e os empresários mais influentes do país.

Aliás, conforme ponderado ao longo do estudo, a colaboração premiada e os acordos de leniência foram fatores importantes no avanço das investigações da Lava-Jato. No que se refere ao comportamento gerado por este instrumento jurídico, observa-se que tanto os investigados quanto o Ministério Público Federal agem de modo a maximizar seus interesses, o que se coaduna com a vertente do institucionalismo da escolha racional. De um lado os acusados buscam a redução da eventual pena fixada, de outro as instituições responsáveis pela condução do processo procuram por informações que possam contribuir para a investigação.

Além disso, um outro comportamento atrelado às investigações, notadamente no que se refere à atuação do Poder Judiciário, diz respeito ao abuso de poder. Partindo do institucionalismo histórico, pode-se considerar que o abuso de poder somente é possível devido a colocação do ator dentro da estrutura de poder, o que lhe autoriza a tomar certas atitudes que, para alguns, está além de sua alçada. De outro modo, pode ser visto, ainda, como uma forma de atingir os interesses pessoais do próprio ator sem se preocupar com a satisfação geral, se enquadrando nas características do institucionalismo da escolha racional. Afinal, a burocracia "constitui um instrumento de poder, de dominação, pois, ninguém pode ser superior à estrutura burocrática de uma sociedade” (FARIA; MENEGHETTI, 2011, p. 427).

Ademais, como uma resposta aos símbolos institucionais gerados pela instituição Lava-Jato, as manifestações populares, principal comportamento da sociedade civil notado, demonstram que os cidadãos estão se mobilizando, ainda que momentaneamente, em busca da defesa de seus interesses, como estabelecido na vertente da escolha racional. Por todo o exposto, observou-se que a Operação Lava-Jato não representa apenas um instrumento de combate à prática de atos corruptos por políticos e seus respectivos partidos, servidores públicos e empresários, mas pode ser considerada, também, um mecanismo importante que tem influenciado diretamente o comportamento dos envolvidos nas investigações.

A teoria neo-institucional, neste sentido, é fundamental para a compreensão de que as práticas sociais constituídas no contexto da Operação Lava-Jato são apresentadas não somente pelas normas e instrumentos formais de controle da corrupção, mas também por elementos simbólicos presentes no governo, nas organizações e na sociedade. As instituições, portanto, são responsáveis por moldar o comportamento dos agentes, o que pode favorecer a prática de condutas que beneficiam interesses próprios.

No caso do controle da corrupção pela Operação da Lava-Jato, as práticas sociais são produzidas, consumidas e reproduzidas a partir das relações existentes nos poderes da república brasileira e, também, da influência da mídia e da sociedade como um todo. Observa-se, na operação, um tipo de arranjo 
institucional que engloba toda a estrutura de governança da administração pública. Entendida, pela lente neo-institucional, a referida operação não se configura apenas como uma instituição de controle externo da corrupção, mas uma instituição que se torna símbolo de uma geração que busca pela cultura da eficiência e justiça no Brasil.

A lente do neo-institucionalismo, assim, permite inferir que as medidas de accountability devem ir para além dos processos formais, das normas e dos mecanismos gerenciais adotados como instrumentos de controle da administração pública. Dessa forma, é relevante compreender que é preciso estabelecer uma cultura da justiça e da eficiência na burocracia pública brasileira, capaz de romper com a gramática política que permeia a tecnocracia brasileira (MOT'TA, 1988; NUNES, 2010), principalmente, quando se observa a atuação dos burocratas brasileiros como participantes ativos da democracia contemporânea, ou seja, capazes de atuar como policymaker. Neste arranjo é imprescindível que os poderes executivo, judiciário e legislativo estabeleçam uma política de governança baseada no ideal republicano e democrático. Pois, se por um lado, a burocracia se torna refém dos interesses da classe política, por outro lado é a principal beneficiária dos interesses da corrupção (LOUREIRO; OLIVIERI; MARTES, 2010).

\section{Considerações finais}

O presente ensaio teve como objetivo analisar, a partir da perspectiva neo-institucional, a Operação LavaJato e os seus consequentes desdobramentos. Para tanto, o estudo narrou o seu desenvolvimento inicial e os acontecimentos posteriores que fizeram com que ela se tornasse a maior operação anticorrupção ocorrida no país. Além disso, buscou-se compreender os principais arranjos institucionais que auxiliam no combate e controle da corrupção burocrática. Frente às considerações apresentadas, a pesquisa destacou como a lente do neo-institucionalismo ajuda a explicar e entender a Lava-Jato como mecanismo de combate à corrupção no setor público brasileiro. Deste modo, diante dos escândalos e denúncias envolvendo políticos e servidores públicos brasileiros nos últimos anos, a Operação Lava-Jato configurase como um instrumento que merece a atenção de pesquisadores do campo de públicas, sobretudo, em razão dos seus consequentes desdobramentos, como a prisão e condenação de políticos influentes, aliados à grande comoção pública feita por parte da mídia.

Além disso, a análise proposta neste trabalho contribui para a discussão sobre democracia e eficiência no Brasil, demonstrando os principais arranjos institucionais vigentes no combate e controle de corrupção. Como já exposto, os atos corruptos são responsáveis por onerar tanto a democracia brasileira, quanto o potencial de uma gestão pública eficiente. Em termos de burocracia, avança-se no debate de que é imprescindível a atuação de instituições de controle interno na administração pública, de modo que estabeleçam-se critérios efetivos de controle e combate dos atos corruptos.

Outro ponto que o estudo tangencia é o papel passivo dos partidos políticos, que no caso da Operação Lava-Jato, restringiram a sua atuação para objetivos de curto prazo e de interesses partidários. Entretanto, Loureiro, Olivieri e Martes (2010) corroboram a ideia de que os partidos políticos precisam assumir seu papel como atores importantes na discussão sobre os rumos políticos e estratégicos do país. Assim, entender as funções da burocracia e suas intercessões com as instituições políticas no Brasil torna-se imprescindível.

Ademais, observou-se o quanto a Operação Lava-Jato influenciou e influencia no cenário político brasileiro, colocando em evidência os agentes e partidos políticos envolvidos em casos de ilegalidades contra a administração pública. Tal fato, inclusive, afetou a votação popular no cenário eleitoral de 2018, demonstrando que diversos agentes políticos envolvidos nos processos de investigações, perderam seus cargos após serem expostos como envolvidos em crimes de corrupção. Considera-se, portanto, que ao trazer à tona uma série de políticos e empresários envolvidos em crimes que minaram recursos da administração pública brasileira, a Operação Lava-Jato acabou gerando na população grande insatisfação contra os representantes políticos, criando um desejo de justiça e anseios por mudança. 
Conclui-se, desta maneira, que a pesquisa realizou uma análise mais profunda das instituições brasileiras de combate à corrupção e dos arranjos políticos que a Operação-Lava-Jato tem acarretado, sobretudo, pela intercessão de instituições de distintos poderes como o Executivo, Legislativo e Judiciário. Assim, pensar em inovações institucionais requer uma análise cuidadosa de como são constituídas as instituições e como se dá o comportamento dos atores nas suas distintas configurações. O caminho dessa discussão, como se tem visto, também se estabelece pelo diálogo com a sociedade civil e para a forma como são construídos os discursos presentes no contexto das mídias sociais e da mass media. Frente a este aspecto, a análise institucional é potencializada pelo entendimento de que as instituições são formadas a partir das práticas sociais compartilhadas.

Cabe questionar, entretanto, que tipo de prática tem sido estabelecida nos locais de debate, bem como, de que maneira tem sido produzida, consumida e reproduzida a agenda de combate à corrupção no Brasil contemporâneo. Apesar de ser tomada por diferentes pontos de vista, a Operação Lava-Jato hoje é uma relevante instituição que coloca na agenda dos pesquisadores do campo de administração pública a necessidade de entender as falhas nos sistemas ideais de gestão, de controle e combate à corrupção, e de regras institucionais.

Quanto às limitações do estudo, vale destacar que a Operação Lava-Jato teve início no ano de 2014 e, em 2019, ainda encontra-se em andamento. Em virtude disso, a pesquisa abarcou apenas parte das investigações que a cada dia apresenta novos desdobramentos e outros casos de corrupção. Ademais, parte das informações sobre as investigações conduzidas foram divulgadas pela mídia, por meio de suas revistas eletrônicas, que constituíram fonte de dados para esta pesquisa, assim como os sites institucionais dos órgãos envolvidos. A mídia, entretanto, não é totalmente neutra quando leva informação ao público, fato considerado na elaboração deste estudo.

Por fim, o presente trabalho é um ponto de partida para a elaboração de estudos que comtemplem a Operação Lava-Jato e a corrupção no contexto da administração pública, contribuindo para a formação de uma nova agenda de pesquisa. A propósito, um ponto a ser discutido diz respeito aos rumos que a operação tem ganhado nos últimos anos, considerando, por exemplo, o fato do juiz que conduziu as investigações iniciais ter sido nomeado Ministro da Justiça, bem como a reestruturação de órgãos de controle no âmbito do governo federal. Outros desdobramos da Operação Lava-Jato, como a discussão sobre a prisão de condenados em segunda instância e a polarização das eleições presidenciais do ano de 2018, são assuntos que também merecem destaque pela academia.

Não se pode negar que as revelações trazidas pela Operação Lava-Jato foi um marco para a administração pública, para o contexto político, influenciando, inclusive, a economia do país. A corrupção sempre esteve presente no contexto brasileiro, a Lava-Jato, entretanto, evidenciou o quanto ela ainda está encrustada, como os mecanismos de controle burocráticos ainda são fracos, no sentido de impedir que ela ocorra e, ao mesmo tempo, como eles podem ajudar na sua identificação e seu combate. Nesse contexto, pesquisas que também abarquem o papel do controle social podem trazer contribuições que permitam encontrar a melhor forma de articular um aparato institucional que realmente impeça, ou que pelo menos diminua, a ocorrência da corrupção no Brasil.

\section{Referências}

ARANTES, R. B.; LOUREIRO, M. R.; COUTO, C.; TEIXEIRA, M. A. C. Controles democráticos sobre a administração pública no Brasil: Legislativo, tribunais de contas, Judiciário e Ministério Público. In: LOUREIRO, M. R.; ABRUCIO, F. L.; PACHECO, R. S. (Org.). Burocracia e política no Brasil: desafios para a ordem democrática no século XXI. Rio de Janeiro: FGV, 2010. p. 109-147.

ASSIS, A. N. Institutionalizing the concept of sustainability from a tetralogical perspectiv: the case of pro-guaíba. Organizações \& Sociedade, 18(57):335-353, 2011. 
AVRITZER, L. "Sociedade civil e participação no Brasil democrático". In: AVRITZER, L. (org.). Experiências nacionais de participação social. São Paulo: Cortez, 2009.

AVRITZER, L.; BIGNOTO, N.; GUIMARAES, J.; STARLING, H. M. M. Corrupção ensaios e críticas, Editora UFMG, 2008.

BARROS, M. Tools of legitimacy: the case of the Petrobras corporate blog. Organization Studies, 35(8): 1211-1230, 2014.

BOBBIO, N. O futuro da democracia: uma defesa das regras do jogo. Tradução de Marco Aurélio Nogueira. São Paulo: Paz e Terra, 2000.

BRANDT, R.; AFFONSO, J.; MACEDO, F. 'O maior ressarcimento na história mundial', afirma Deltan nas redes. 2016. Disponível em: <http://politica.estadao.com.br/blogs/fausto-macedo/o-maiorressarcimento-na-historia-mundial-afirma-deltan-nas-redes/>. Acesso em: 24. abril.2017.

BRASIL. Constituição da República Federativa do Brasil. Brasília: Senado, 1998.

BRASIL. Lei n ${ }^{\circ} 12.850$, de 2 de agosto de 2013. Define organização criminosa e dispõe sobre a investigação criminal, os meios de obtenção da prova, infrações penais correlatas e o procedimento criminal; altera o Decreto-Lei no 2.848, de 7 de dezembro de 1940 (Código Penal); revoga a Lei no 9.034, de 3 de maio de 1995; e dá outras providências. Diário Oficial [da] República Federativa do Brasil, Brasília, DF, 05.08.2013. Disponível em: <http://www.planalto.gov.br/ccivil_03/_ato20112014/2013/lei/112850.htm>. Acesso em: 24. abril.2017.

BRASIL. Ministério da Transparência, Fiscalização e Controladoria Geral da União. Ministério da Transparência, Fiscalização e Controle mantém funções da antiga CGU. 2016. Disponível em: <http://www.cgu.gov.br/noticias/2016/05/ministerio-da-transparencia-fiscalizacao-e-controlemantem-funcoes-da-antiga-cgu>. Acesso em: 24. abril.2017.

BRASIL. Polícia Federal. Ministério da Justiça e Segurança Pública. Operação Lava-Jato. 2017a. Disponível em: <http://www.pf.gov.br/imprensa/lava-jato>. Acesso em: 24. abril.2017.

CALDAS, O. V.; COSTA, C. M.; PAGLIARUSSI, M. S. Corrupção e composição dos gastos governamentais: evidências a partir do Programa de Fiscalização por Sorteios Públicos da ControladoriaGeral da União. Rev. Adm. Pública, 50(2):237-264, 2016.

CARvalho, C. A.; VIEIRA, M. M. F.; SILVA, S. M. G. A trajetória conservadora da teoria neoinstitucional. Gestão. Org - Vol. 10, n. Especial, p. 469-496, 2012.

CARvalho, J. M de. Passado, Presente e futuro da corrupção brasileira. In. Corrupção: Ensaios e críticas. Leonardo Avritzer et. al (orgs). Belo Horizonte, Editora UFMG, 2008.

CAVALCANTE, P. Descentralização de políticas públicas sob a ótica neoinstitucional: uma revisão de literatura. Revista de Administração Pública, 45(6): 1681-1804, 2011.

CECHELAINE, C. H. O.; SILVEIRA, M. C.; OLIVEIRA, K. P.; MORAES, C. E. S. A influência dos processos de institucionalização na utilização dos resultados de avaliações de políticas públicas: o caso mineiro das avaliações executivas de projetos. Contabilidade, Gestão e Governança, 16 (1):82-97, 2013.

CHADE, J. Lava-Jato ganha principal prêmio anti-corrupção. ESTADÃO. 2016. Disponível em: $<$ http://politica.estadao.com.br/noticias/geral,lava-jato-ganha-principal-premio-anticorrupcao,10000092336>. Acesso em: 24. abril. 2017.

COLLEONI, E.; ROZZA, A.; ARVIDSSON, A. Echo chamber or public sphere? Predicting political orientation and measuring political homophily in Twitter using big data. Journal of Communication, 64 (2): 317-332, 2014. 
DIMAGGIO, P. J.; POWELL, W. W. Introducción. In: POWELL, W. W.; DIMAGGIO, P. J. (Eds.). El nuevo institucionalismo en el análisis organizacional. México: Fondo de Cultura Económica. 2001.

ESTADÃO. Limitações da Lava-Jato. 2017a. Disponível em: < http://opiniao.estadao.com.br/noticias /geral,limitacoes-da-lava-jato,70001691029>. Acesso em: 19. março. 2017.

ESTADÃO. Uma Longa Espera. 2017b. Disponível em: <http://opiniao.estadao.com.br/noticias/ geral,uma-longa-espera,70001703311>. Acesso em: 19. março. 2017.

FARIA, J. H de; MENEGHETTI, F. K. Burocracia como organização, poder e controle. Revista de Administração de Empresas, 51(5): 424-439, 2011.

FIALHO, R. C. N.; MARTINS, R. Elementos institucionais e desempenho da logística de uma rede pública de assistência farmacêutica. Revista de Administração Pública, 50(5): 129-149, 2016.

FILGUEIRAS, F. A corrupção na política: perspectivas teóricas e metodológicas. Cadernos Cedes, IUPERJ, no 5, p. 1-28, 2006.

FILGUEIRAS, F. Sociedade civil e accountability societal no controle da corrupção no Brasil. In XXXV Encontro Anual da ANPOCS. Anais. Belo Horizonte-MG, 2011b.

FILGUEIRAS, F.; ARANHA, A. L. M. Controle da Corrupção e Burocracia da Linha de Frente: Regras, Discricionariedade e Reformas no Brasil. Revista de Ciências Sociais, 54(2): 349 -387, 2011.

GOMES, M. A de M. Crítica à cobertura midiática da Operação Lava-Jato. Revista Brasileira de Ciências Criminais. RBCCRIM. VOL. 122, 2016.

GUERREIRO RAMOS, A. A sociologia de Max Weber (sua importância para a teoria e a prática da Administração). Revista do Serviço Público, v. 57, n. 2, p. 267-282, 2006.

GUIMARÃES, J. Culturas brasileiras da participação democrática. In: AVRITZER, L. (Org.). Experiências nacionais de participação social. Belo Horizonte/São Paulo: UFMG/Cortez, 2010. 13$26 \mathrm{p}$.

HALL, P. A.; TAYLOR, R. C. R. As três versões do neo-insitucionalismo. Lua Nova, n 58, p. 193-223, 2003.

IMMERGUT, E. M. "The Theoretical Core of the New Institutionalism". Politics and Society, vol. 26, $\mathrm{n}^{\mathrm{o}}$ 1, p. 5-30, 1998.

JACKSON, L.; VALENTINE, G. Emotion and politics in a mediated public sphere: Questioning democracy, responsibility and ethics in a computer mediated world. Geoforum, 52, 193-202, 2014.

JENSEN, J.; MÉRAND, F. Sociology, institutionalism and the European Union. Comparative European Politics, Vol. 8, 1, 74-92, 2010.

KHAN, M. N. A typology of corrupt transaction in developing countries. IDS bulletin: Liberalization and the New Corruption, 27(2), 12-21, 1996.

KLITGAARD, R. Controlling Corruption. Berkeley: University of California Press, 1998.

LAMEIRÃO, C. R. Estratégias Políticas e Gestão Local: as subprefeituras do município do Rio de Janeiro. 127. Dissertação - Universidade Federal Fluminense. Niterói, 2007.

LOUREIRO, M. R.; OLIVIERI, C.; MARTES, A. C. Burocratas, partidos e grupos de interesse: o debate sobre política e burocracia no Brasil. In: LOUREIRO, M. R.; ABRUCIO, F. L.; PACHECO, R. S. (Orgs.). Burocracia e Política no Brasil: desafios para a ordem democrática no século XXI. Rio de Janeiro: Editora FGV, 2010. 
LUBENOW, J. A. A esfera pública 50 anos depois: esfera pública e meios de comunicação em Jürgen Habermas em homenagem aos 50 anos de Mudança estrutural da esfera pública. Trans/Form/Ação, Marília, v. 35, n. 3, p. 189-220, 2012.

MARCH, J. G.; OLSEN, J. P. Neo-Institucionalismo: Fatores Organizacionais na Vida Política. Rev. Sociol. Polít., Curitiba, v. 16, n. 31, p. 121-142, 2008.

MATIAS-PEREIRA, J. Reforma do Estado e controle da corrupção no Brasil. Caderno de Pesquisas em Administração, São Paulo, v. 12, n. 2, p. 1-17, 2005.

MELO, F. L. N. B de; SAMPAIO, L. M. B; OLIVEIRA, R. L de. Corrupção Burocrática e Empreendedorismo: Uma Análise Empírica dos Estados Brasileiros. Revista de Adm. Contemp. RAC, Rio de Janeiro, v. 19, n. 3, art. 5, p. 374-397, 2015.

MORAES, L. F. R de; MAESTRO FILHO, A. D.; DIAS, D. V. O paradigma weberiano da ação social: um ensaio sobre a compreensão do sentido, a criação de tipos ideais e suas aplicações na teoria organizacional. Rev. adm. contemp., Curitiba, v. 7, n. 2, p. 57-71, 2003.

MORAES, R. L.; ANDION, C.; PINHO, J. L. Cartografía de las controversias en la arena pública de la corrupción electoral en Brasil. Cad. EBAPE.BR [online], v. 15, n. 4, p. 846-876, 2017.

MOTTA, F. C. P. As formas organizacionais do estado. Rev. adm. empres., São Paulo, v. 28, n. 4, p. 15-31, 1988.

MPF. Ministério Público Federal. 10 Medidas contra a corrupção. 2017b. Disponível em: <http://www.dezmedidas.mpf.mp.br/>. Acesso em: 24. abril.2017.

MPF. Ministério Público Federal. Caso Lava-Jato. 2017a. Disponível em: <http://www.pf.gov.br/imprensa/lava-jato>. Acesso em: 24. abril.2017.

NASCIMENTO, E. O. do. Os Novos Institucionalismos na Ciência Política Contemporânea e sua Integração Teórica. Revista Brasileira de Ciência Política (Impresso), v. 01, p. 95-121, 2009.

NORTH, D. Institutions, Institutional Change and Economic Performance. Cambridge: Cambridge University Press, 1990.

NUNES, E. O. A Gramática política no Brasil: clientelismo e insulamento burocrático. 4 ed. - Rio de Janeiro: Garamond, 2010, 144p.

OUTEIRO, G. M.; GÓES, D. S.; NASCIMENTO, D. M. Neoinstitucionalismo, regularização fundiária urbana e o Programa Terra Legal. Novos Cadernos NAEA, v. 19 n. 2, p. 115-137, 2016.

PAIVA, A. L.; GARCIA, A. S.; ALCÂNTARA, V. C. Representações e Disputas Discursivas sobre a Corrupção no Brasil: uma Análise Crítica na Rede Social Twitter. In. IX Encontro de Estudos Organizacionais da ANPAD, Anais do ENEO, Belo Horizonte, 2016.

PERES, P. S. Comportamento ou Instituições? A evolução histórica do neo-institucionalismo da ciência política. Revista Brasileira de Ciências Sociais, v. 23, n. 68, p. 67-71, 2008.

PNUD - Programa das Nações Unidas para o Desenvolvimento. A Democracia na América Latina rumo a uma democracia de cidadãs e cidadãos. São Paulo: LM\&X, 2004.

POWER, T. J.; TAYLOR, M. M. Accountability Institutions and Political Corruption in Brazil. In POWER, Timothy J; TAYLOR, Matthew M. (Eds) Corruption and Democracy in Brazil: The Struggle for Accountability. University of Notre Dame Press, 2011.

RIBEIRO, F. Institucionalismo da escolha racional e institucionalismo histórico: divergências metodológicas no campo da Ciência Política. Pensamento Plural, Pelotas [10]: 89-100, 2012.

RICCITELLI, A. Em ano eleitoral, os eleitores precisam de cuidados para saber o real impacto que as investigações terão sobre os candidatos do pleito; entenda. ÚLTIMO SEGUNDO. 2018. Disponível em: 
<https://ultimosegundo.ig.com.br/colunas/antonio-riccitelli/2018-04-16/lava-jato-eleicoes2018.html>. Acesso em: 7. março.2019.

RITT, C. F. Políticas Públicas e Privadas para o Combate à Corrupção em Face da Lei 12.846/2013: O Acordo de Leniência como política pública para combater a corrupção instalada e o Compliance como política privada para evitar práticas corruptivas no ambiente empresarial. Santa Cruz do Sul, RS. Tese. Universidade de Santa Cruz do Sul, 2017, 259 p.

ROSE-ACKERMAN, S. Corruption: a study in Political Economy. Nova Iorque: Academic Press, 1978. ROSE-ACKERMAN, S. The institutional economics of corruption. In: Graaf, G.; Maravic, P.; Wagenaar, P. The good cause: theoretical perspectives on corruption. Barbara Falls, MI, EUA: Barbara Budrich Publishers, p. 47-63, 2010.

SILVA, E. A.; PEREIRA, J. R.; ALCÂNTARA, V. C. Interfaces epistemológicas sobre administração pública, institucionalismo e capital social. Cad. EBAPE.BR, v. 10, nº 1, artigo 2, Rio de Janeiro, 2012.

SOARES, J. B. Inovações Institucionais para a Gestão dos Recursos Hídricos no Âmbito Federal. Rio de Janeiro: UFRJ/IFCS, 2005. 131 f. Tese (Doutorado) - Programa de Pós-Graduação em Sociologia e Antropologia, Universidade Federal do Rio de Janeiro, 2005.

SOUZA, F. J. B.; SILVA, S. A. M; GOMES, A. O. Corrupção no Setor Público: Considerações a Partir da Literatura Internacional. In: EnAnpad, Anais, São Paulo, 2017.

THÉRET, B. As instituições entre as estruturas e as ações. Lua Nova, São Paulo, n. 58, p. 225-255, 2003.

VAARA, E.; TIENARI, J. On the narrative construction of multinational corporations: An antenarrative analysis of legitimation and resistance in a cross-border merger. Organization Science, 22(2), 370-390, 2011.

VENTURA, T. Democracia e participação. Inovações democráticas e trajetória participativa no Brasil. Cadernos EBAPE.BR, v. 14, n. 3, p. 705-720, 2016.

WEBER, M. Ensaios de sociologia. 5. ed. Rio de Janeiro: LTC Editora, 1982. 